Acta Poetica 25-1

PRIMAVERA

2004

\title{
Luciano de Samosata y George Méliès: dos viajes a la Luna, una poética
}

\begin{abstract}
Alejandro Mendoza Pérez
Partiendo de la idea de que el filme El viaje a la Luna de George Méliès tuvo que haberse inspirado, directa o indirectamente, en un fragmento de Historias verdaderas de Luciano de Samosata, se hace un recuento de cada ficción buscando los puntos de encuentro, con la finalidad de indagar en torno a los orígenes de la adaptación de temas literarios a la cinematografía.

The starting point of this notes is the idea that Georges Méliès' film, Voyage dans la Lune, was influenced in some way by Lucian's Truthful Stories. Both fictions are reviewed here, looking at the similarities between them, with the purpose of getting a better understanding of how, in its origins, literature motives were adapted to cinematography.
\end{abstract}




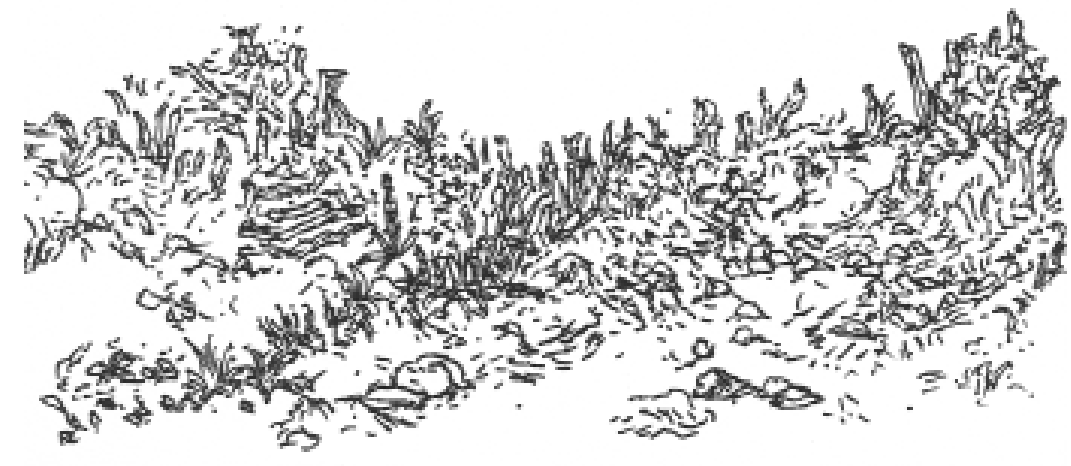


Acta Poetica 25-1

PRIMAVERA

2004

Alejandro Mendoza Pérez

\section{Luciano de Samosata y George Méliès: dos viajes a la Luna, una poética}

Azorín dijo alguna vez que antes de Georges Méliès el cine propiamente dicho no existía: lo que había eran vistas. Al crear los argumentos dentro del cine, Méliès fue el verdadero fundador de este arte. Una tarde de 1933, el cineasta francés reconoció, en respuesta a una entrevista del británico J. A. Le Roy, que la idea de El viaje a la Luna (1902) le había venido a la mente a partir de dos novelas de Julio Verne: De la tierra a la Luna y Alrededor de la Luna (González Dueñas 2001, 304). Sin embargo esta confesión, en parte honesta, escondía en su interior un despiste del que serían víctimas los estudiosos del cine del pasado y, por carambola, los del presente, que han observado que, además de la obra de Verne, El viaje a la Luna de Méliès se inspira también en la opereta de Jaques Offenbach, de 1876. En apariencia nadie tomó en cuenta un aspecto esencial de la poética del fundador del cine: Georges Méliès era no sólo hombre culto sino más que cualquier otra cosa, un mago, todo un ilusionista o "prestidigitador por vocación", gestado dentro de la más excelsa tradición (aprendió ilusionismo con el famoso Robert Houdin), donde confesar el truco, en este caso su fuente de inspiración para la trama del trayecto espacial, era equivalente a contradecir la magia. 
Es cierto, de Julio Verne, Méliès tomó el procedimiento para llegar al espacio exterior: el largo cañón y el singular cohete. ¿Pero de dónde sacó las mejores piezas de su ficción: un satélite con rostro, el descubrimiento del planeta tierra a lo lejos, los hongos mutantes, selenitas maromeros, un rey lunar que hace prisioneros a los astronautas, las frenéticas persecuciones, y toda una visión narrativa empapada por variables onírico sarcásticas? Imposible resolver esta cuestión del todo, pues las referencias del realizador cinematográfico son múltiples. En su obra está presente una amplia gama de seres mitológicos y fantásticos, sin excluir la esporádica presencia de ciertos eventos de actualidad; sin embargo, es patente que en su ficción adapta — pues transporta una narración de un lenguaje a otro; de los linderos literarios a las veredas cinematográficas - un considerable número de ingredientes, directa o indirectamente, de la hazaña celeste plasmada en Historias verdaderas del escritor sirio del siglo II, Luciano de Samosata.

A la luz de tantos estudios recientes donde se indaga el cómo y cuándo el cine ha influido en las letras, parece pertinente hacer un alto, regresar a aquellos lectores que fueron los creadores del cine como Méliès y rastrear la historia de una de las primeras y más gozosas mudanzas de una narración en prosa hacia un sensible universo plástico. Desde luego, antes de despegar, es bueno recordar que George Méliès leía bien el griego y era gran lector de los clásicos griegos y latinos, además de tener gran afición al teatro; era devoto de Goethe (hizo múltiples versiones del Fausto), de Shakespeare (también hizo una versión de Hamlet), Cervantes, Rabelais, Daudet, Hoffman, Dunsany, además de hacer versiones de otras obras inglesas como Robinson Crusoe y Rip van Winkle (González Dueñas, 116). Era, al igual que Luciano (que en su Verdadera historia parodió a los narradores de viajes), afecto a las parodias.

Así como el ampliamente helenizado samosatense satirizó, reduciendo al absurdo, los exagerados relatos de viajes de su 
tiempo, de forma parecida el prestidigitador francés Georges Méliès optó por caricaturizar las ambiciones científicas de su época. Ambos, más que preocupados por un apego a la verdad en sus obras, buscaron ante todo fascinar y entretener a su público (aquí podría señalarse una sintomática diferencia entre ambos: Julio Verne se documentó profusamente para producir su trabajo de ficción; Méliès, en cambio, retrocede y plantea una luna en forma de un disco plano, aunque sabía que no era así). Julio Verne buscó cautivar a su público a través de las letras griegas, la herramienta expresiva a su alcance y con la que demostró una gran habilidad no sólo en cuanto a vocabulario y erudición sino también por su elegante estilo, desbordante imaginación y humor. Méliès, mediante su sensibilidad visual, soltura narrativa e infinitos trucajes, la mayoría de los cuales fueron utilizados por primera vez en sus películas. La relación entre ambos creadores, separados por tantos siglos, bien puede parecer forzada. Sin embargo la evidencia en el caso de sus recorridos extraterrerestres - cuyos argumentos revisaremos a continuación - demuestra claras similitudes entre los dos. Si bien el contacto entre ambos poetas no fue directo, tuvo que haber entre ellos un contacto indirecto, pues las posibilidades de que Méliès no haya leído a ninguno de los tantos autores que imitaron a Luciano son escasísimas.

Luciano, por otra parte, es quizás la pluma más influyente en cuanto a relatos lunares se refiere. Su permanencia en la literatura posterior es enorme. Sus repercusiones abundan durante el Renacimiento y en el Siglo de Oro español, pero fue en Francia, el país que vio nacer a Méliès, donde Luciano tuvo un peso particularmente significativo, especialmente a partir del siglo XVII: en autores como Rabelais, Fontenelle, Fénelon, Voltaire, Cyrano de Bergerac y muchos más hasta arribar a Julio Verne, ya entrado el siglo XIX.

De no haber tomado Méliès varias de sus ideas directamente de las Historias verdaderas de Luciano, puede que las 
haya leído y adquirido entonces de sus imitadores, entre los que se encuentran escritores de diferentes naciones como H. G. Wells (de quien, al parecer, tomó la ocurrencia de los hongos crecientes). En sus anuncios callejeros, Méliès colocaba un letrero promocionando "Vistas que se salían de lo ordinario... verdaderas obritas fantásticas y pequeñas comedias". Y Luciano, en la presentación de su novela Historias verdaderas, anuncia que "No sólo les atraerá lo novedoso del argumento, ni lo gracioso de su plan, ni el hecho de que contamos mentiras de todos los colores de modo convincente y verosímil" (Luciano, 179).

En estas palabras, que no son más que cordiales y seductoras invitaciones a un par de universos regidos bajo su propio tiempo, se miran de frente dos creadores en plena madurez artística. Si el uno influyó al otro de forma vertical, siempre será un secreto que, tal vez por respeto a la magia, deba permanecer así; pero la evidencia, retratada en sus tramas, permite al menos una leve aproximación a lo que es tal vez una de las más acertadas traducciones en cuanto a contenido connotativo se refiere.

El análisis puede darse en dos sentidos: el primero, del libro de Luciano hacia el guión de cine o, más propiamente, hacia el libreto con el cual se filmaba. En este caso aún nos encontramos dentro de los terrenos literarios. En el segundo caso, de la literatura rumbo a la pantalla, el asunto es más complicado. Y sin embargo, vale la pena detenerse en él, pues es ahí donde la emoción esencial se mantiene y, paradójicamente, se acorta la separación entre ambos autores.

Una vez aclarado este punto es necesario revisar ambas aventuras. La navegación a la luna de Luciano, después de un breve pero apasionado alegato en favor de la ficción, se perfila del siguiente modo: partiendo de las columnas de Hércules el personaje principal ${ }^{1}$ tiene el propósito de descubrir qué hay al

\footnotetext{
${ }^{1}$ Aunque este personaje no lleva el nombre de Luciano, bien puede ser su alter ego debido a su estilo narrativo, que coincide con el que usa el autor cuando
} 
final del océano, de conocer, también, a la gente que allá mora. Navegan en un principio con viento favorable, pero al segundo día los invaden las tinieblas. Permanecen bajo la tempestad durante ochenta días, tras los cuales divisan una isla.

Desembarcan algunos y van a explorar el territorio. Encuentran una estela y un par de huellas gigantes. Siguen su camino y se topan con un río de vino; al buscar su fuente, dan con vides que gotean la bebida. Comen peces de esta corriente y terminan borrachos. Luego atraviesan el río y hallan vides, pero esta vez con mujeres encima que les dan la bienvenida con besos embriagantes. Los que van a sus brazos quedan trabados por la parte del sexo y se convierten en seres atados como ellas. Los sobrevivientes corren hacia la nave donde relatan a sus colegas la desventura. Toman agua y disponen la partida.

$\mathrm{Al}$ mediodía un torbellino los arrastra hacia el cielo. Permanecen volando durante ocho días sin poder descender, e incluso avistan, desde lo lejos, lo que parece ser tierra, brillante y esférica, en medio del aire. La fondean y logran desembarcar. Examinan la región, esperanzados de encontrarse en su tierra, cuando son capturados por los cabalgabuitres que los llevan directamente con el rey del lugar para pasar por un interrogatorio. Los marineros le cuentan su historia y el rey la suya, haciéndoles saber también que están sobre la superficie lunar y que aquella esfera que antes vieron es el planeta tierra. El mandatario selenita les ofrece hospedaje y una vida repleta de felicidad si concluye su guerra contra los habitantes del sol. Después de que les hace saber la causa de la disputa, los marineros aceptan pelear a su lado.

Al otro día las filas están listas para la gran batalla, el protagonista describe los ejércitos y los armamentos. Las arañas de

aparece como narrador. Aquí estriba, precisamente, otra de las "coincidencias" entre Méliès y Luciano porque los dos eran afectos a participar dentro de sus propias obras. En el caso de Méliès basta con mencionar que él mismo actúa como el Comandante de la misión luna en El viaje a la Luna. 
la infantería tejen entonces una red entre la luna y el sol. Se describen las huestes enemigas. Rebuznan los asnos e inicia la pugna. Se narra, con lujo de detalles, la apabullante victoria de los selenitas. Las nubes se llenan de sangre y están erigiendo los trofeos cuando aparecen de pronto los nubicentauros con hombres gigantes. Lo destrozan todo y asesinan a muchos, capturando al protagonista junto con sus compañeros. Todos son llevados al sol.

La gente del sol acepta un intercambio y perdona a la luna, brindándole la luz de la que la había privado con un muro de nubes. Los representantes de los dos astros hacen las paces y los prisioneros son devueltos. El protagonista y sus acompañantes son invitados a permanecer en la luna, y a quedarse con uno de los territorios que originó la disputa. Ellos no aceptan la oferta, pero se quedan allí siete días, y es así como tienen oportunidad de ver con detalle las rarezas y maravillas de la luna. El personaje describe cómo es allí la vida: no tienen mujeres, hay matrimonios homosexuales, los embarazos son en las pantorrillas. Hay también una descripción de los arbóreos, hombres que nacen de árboles nacidos de un testículo cortado, que cuentan con miembros sexuales artificiales. Al leer este pasaje es inevitable recordar el estilo que usa Heródoto para sus descripciones de tierras lejanas.

También se hace referencia a algunas costumbres particulares: se disuelven en humo en lugar de morir, tras lo cual todos se alimentan del humo de las ranas que asan. Por bebida toman lo que exprimen del aire. No orinan ni tienen orificios para defecar, sólo cuentan con uno, que es por donde copulan, atrás de la rodilla. Nos platica algunos de sus cánones estéticos: los calvos son guapos y los melenudos son feos (lo cual representa lo inverso del gusto griego), así como otros detalles extraños: el hecho de que muestren barbas en las rodillas, un sólo dedo, coles en los traseros. También es curiosa la sustancia que les sale de la nariz, su modo de fabricar el aceite, los 
usos que le dan a sus barrigas sin tripas (como por ejemplo, contenedores del frío), la vestimenta y los rasgos faciales singulares, tales como los ojos desmontables, hojas de plátano en lugar de las orejas. Y así continúa la descripción, yendo a otros asuntos maravillosos como el enorme espejo que se halla en la boca de un pozo por el que se puede ver todo lo que acontece a la distancia, en el caso de los exploradores, en la tierra.

Los visitantes se despiden del rey y, antes de zarpar, reciben regalos. Mil cabalgabuitres los escoltan durante quinientos estadios. Los navegantes continúan su travesía por el Lucero del Alba y después por el zodiaco. Rozan la tierra, pero las condiciones les son adversas para un aterrizaje, por lo que deben de seguir navegando en el espacio. Se topan con un ejército; sin embargo, gracias a que se encuentran amparados por el tratado de paz, pueden continuar. Llegan a la ciudad de las lámparas, donde el narrador nos ofrece, una vez más, toda una descripción de las costumbres y la gente. Incluso, el protagonista halla su propia lámpara, que le da nuevas sobre sus seres queridos en la tierra. ${ }^{2}$

Prosiguen su navegación, pasan cerca de Nubicuculia. Y finalmente, cuatro días después logran posarse sobre las tranquilas aguas de la tierra (en el viaje de Méliès —en las secuencias 13 y 14- el regreso a la tierra se realiza también por las aguas del mar). Con esto finaliza la travesía extraterrena de Historias verdaderas para continuar, durante un buen número de páginas, con otras coordenadas no menos fascinantes.

El filme El viaje a la Luna de Georges Méliés retrata, si lo presentamos a modo de sinopsis, lo siguiente: un científico reúne una delegación dispuesta a viajar a la luna. Emprenden el trayecto en un cohete. Se encuentran con un territorio hostil

\footnotetext{
${ }^{2}$ El motivo de las lámparas vivientes parece ser también común en el cine fantástico. El último ejemplo, y tal vez uno de los más poéticos, lo hallamos en otra cinta de animación de Disney: El viaje de Chihiro (Sen to Chihiro no kamikakushi, 2001) del director japonés Hayao Miyazaki.
} 
y se duermen para recuperarse. Las divinidades celestes les envían nieve y ellos se ven obligados a refugiarse en un cráter, donde encuentran criaturas extrañas. Unas de ellas son selenitas que terminan capturándolos. Son llevados ante el mandatario de la luna, pero uno de los terrícolas escapa y lo ataca. Por útimo huyen y regresan a la tierra con vida.

Esta breve aventura, que para su tiempo significó una enorme esfuerzo (tres meses de producción y una considerable cantidad de francos) está distribuida de la siguiente manera:

1) Una veintena de astrónomos exóticamente vestidos (pelucas, sombreros cónicos, collarines) se reúnen en un amplio salón donde ya hay varios asistentes que lucen muy inquietos. Entra el Gabinete y todos toman asiento. Seis bellas edecanes les entregan seis enormes telescopios. La calma reina en el lugar y aumenta cuando arriba el Presidente, un hombre robusto con un disfraz color negro de mago, lleva un sombrero cónico y un sol estampado, junto a varias estrellas y la luna, en la parte de atrás de su traje. Se dirige al pizarrón donde hay una ilustración: dos esferas, una mayor que la otra. El Presidente sube y toma su lugar, se le cae el sombrero mientras empieza a explicar a los miembros su proyecto de realizar un viaje a la luna. El auditorio toma asiento y lo escucha con atención, interrogan al Presidente e incluso debaten entre ellos hasta que éste toma un gis, dibuja un cohete encima de la esfera más grande (la tierra) y traza una línea curva hacia la segunda esfera (la luna). Varios asistentes se ponen de pie alarmados por la propuesta y discuten con pasión. El Gabinete defiende la propuesta e inicia una ardua polémica en el salón. El Presidente trata de darse a entender y, como no lo logra, coge el libro más próximo a él y lo arroja con fuerza sobre sus interlocutores. Después hace lo mismo pero con todos los papeles de su escritorio. Los ánimos se han calmado un poco y el Presidente sale de su estrado y dialoga una vez más. El auditorio parece arrepentido de su conducta y se muestra más reflexivo. En la parte 
de arriba algunos miembros siguen discutiendo y analizando la propuesta. El Presidente decide algo: tal vez emprenderá el viaje a la luna solo, y el Gabinete parece querer convencerlo de que no lo haga. Se aproximan a él y lo rodean. Finalmente deciden acompañarlo: las edecanes traen los trajes para el viaje. Se empiezan a desnudar y se colocan unos nuevos trajes, que incluyen otro estilo de sombreros y sacos y chalecos más cortos. El Presidente parece muy entusiasmado y elige a cinco colegas como acompañantes: Nostradamus, Acofribas, Omega, Nicomegas y Parafaragaramus.

(2) Nos encontramos en un enorme taller, ocho hombres, entre herreros, carpinteros, mecánicos, diseñadores, etc. trabajan entre la herramienta. En medio hay un cohete con una de sus partes posteriores abierta. Aparece el Presidente con los viajeros y juntos observan la nave, al parecer les agrada pues alzan las manos maravillados. Saludan a los trabajadores, felicitándolos por su labor. Ingresan al artefacto y lo exploran. Al salir, Nicomegas cae en una tina, sus compañeros lo sacan. Un obrero los invita a subir al techo del taller para ver la fundición y ellos lo siguen. Suben por unas escaleras. Los trabajadores siguen perfeccionando la nave espacial y los próximos viajeros a la luna salen por la parte de arriba.

(3) En la azotea donde se encuentran se ven enormes chimeneas que expulsan humo en cantidades exuberantes, los techos de las casas parecen minúsculos frente a los de las fábricas. El Presidente aparece dando explicaciones en una esquina; uno de ellos porta un telescopio. De pronto, en una de las chimeneas del lado izquierdo aparece una bandera, es la señal de que el artefacto va a ser fundido. Todos se pelean por ver el suceso, de pronto vivimos una enorme explosión, el humo crece por todo el paisaje emitiendo vapor. Los científicos parecen muy entusiasmados y comentan el evento, yendo de un lado para otro.

(4) Sobre los techos de la ciudad un oficial vestido de negro saluda con mucha solemnidad a los viajeros que se preparan 
para abordar, hay edecanes dispuestas por todos lados. El Presidente llega con sus acompañantes y saludan a una multitud que nunca vemos pero que sabemos que está abajo. El cohete avanza, dos damas colocan una escalera frente a la compuerta. Los astronautas abordan entre tropiezos mientras charlan, sonrientes, entre ellos. Dos de ellos llevan sus paraguas. Una vez que han entrado, las edecanes cierran la compuerta y retiran la escalera. El hombre de negro da la orden, el cohete avanza, empujado por las bellas edecanes, hacia el cañón hasta que penetra por completo. Las edecanes se quitan sus sombreros y nos saludan.

(5) El cañón está cargado, de frente vemos su increíble longitud que se alarga hasta los confines del cielo. Hay dos hombres, uno vestido de blanco, junto al cañón, y otro de negro con una espada. Entran las edecanes con la bandera francesa mientras el hombre de blanco dispone una escalera en la que se sube con una vara que tiene fuego en la punta. Las damas edecanes sacan las trompetas y el hombre de negro da la orden de lanzar el cohete y lleva el fuego a la mecha. Sale humo de la punta del cañón y gente, vestida de manera urbana, aparece y festeja.

(6) Vemos un cielo oscuro rodeado de nubes. A lo lejos se ve la luna, nos acercamos a ella con rapidez y las facciones de una cara van tomando forma, tiene la lengua de fuera. Repentinamente, la nave espacial aterriza sobre su ojo derecho, embarrando los alrededores como si se tratara de un pastel. Nos acercamos aún más y vemos con mayor detalle el brusco aterrizaje. La luna gesticula algo a manera de queja.

(7) La nave aterriza sobre una superficie rocosa, se desliza un poco y pronto se abre una puerta de la que sale uno de los tripulantes con su paraguas. Eleva los brazos, explora los alrededores y parece decirle algo a sus acompañantes, que, con sus sombreros elegantes y sus paraguas, también salen del cohete, pero con más calma. Los seis astronautas admiran el pai- 
saje y elevan los brazos llenos de alegría. Su nave ha desaparecido cuando ellos se mueven hacia la derecha, el fondo del horizonte de la luna desciende y aparece en la oscuridad del cielo el planeta tierra. En él sobresale el continente africano. Siguen su curso hacia arriba hasta desaparecer. Los exploradores se proponen avanzar entre el accidentado terreno, pero una explosión sorpresiva los derriba. Sale fuego. Luego, quejándose, se ponen de pie y avanzan por el mismo lugar, adoloridos. Se ven muy cansados, bostezan, estiran los brazos, se quitan las gabardinas, se tienden sobre el suelo y se recuestan en la superficie lunar para dormir un poco. Mientras duermen, un cometa cruza sobre ellos; luego se ven siete estrellas muy grandes: la Osa Mayor. Del centro de cada estrella surgen rostros de mujeres, no parecen contentas con la presencia de los visitantes. Ellas desaparecen y dan lugar, en un territorio onírico, a visiones más elaboradas: Saturno está dentro de un planeta anillado. Hay una dama sentada en la luna que le señala a los durmientes, Saturno se cruza de brazos (parece molesto), y ella hace traer una tormenta de nieve. También hay dos jovenzuelas abrazadas, una de ellas sostiene una estrella en lo alto. Cae más y más nieve hasta que los exploradores despiertan congelándose, se sacuden la nieve de los trajes y brincan para no perder el calor de sus cuerpos. Descienden por un cráter y, uno por uno, van desapareciendo mientras se adentran en la profundidad de la luna.

(8) Estamos dentro de una especie de caverna. Arriba se ve una entrada de luz desde donde también viene una corriente de agua. Hay muchos hongos gigantes a la vera de la barranca. Los terrícolas ingresan por el lado izquierdo avanzando con cautela. Se atropellan en sus observaciones, señalan alguna planta o algún fenómeno que los sorprende y hablan en grupos de dos o tres. Uno de ellos se aventura al lado derecho del canal y abre su sombrilla para comparar su tamaño con el del hongo pero, para sorpresa de todos, el paraguas 
genera raíces y se convierte pronto en un hongo que crece de manera vertiginosa. De la parte de atrás del hongo una criatura extraña, un selenita, aparece. Se mueve más como un animal aunque tiene forma humana, excepto por su extraña cabeza de la que salen picos. También en su andar hay algo extraño, cuando se acerca a los exploradores, presumiblemente para atacarlos, mete las manos debajo de las piernas y avanza usando los brazos a manera de pies. El astrónomo toma un paraguas, se acerca a él y lo ataca sin piedad. Al ser golpeada por la sombrilla, la criatura explota, pero pronto aparece otro selenita, mucho más decidido y con diferente anatomía. En este caso, aunque se mueve también apoyándose con los brazos, muestra la totalidad de su esqueleto. Le dan un golpe y explota. Los exploradores avanzan para salir del cráter pero aparece una cuadrilla de selenitas. Vemos huir a los exploradores mientras los extraterrestres brincan hacia ellos.

(9) Estamos en un salón lujoso decorado de una forma muy particular: picos en las bardas, entradas circulares, adornos en las paredes. Es el palacio del monarca selenita que se encuentra sobre su enorme trono, rodeado por mujeres estrella - las estrellas vivientes - y varios soldados con armaduras y lanzas. Se levanta el rey de la luna, que tiene manos de cangrejo con pulseras, dos enormes ojos salientes, y filosos picos en la parte frontal del rostro. Da la orden de que traigan a los astrónomos recién capturados y ellos entran maniatados, escoltados por otros soldados. Advertimos que aún llevan sus paraguas sujetos entre los brazos y los cuerpos. Uno de los prisioneros, en un acto sorpresivo, se libera y se arroja sobre el rey de la luna, lo toma y lo levanta para hacerlo azotar en el piso. Explota y los terrícolas salen corriendo mientras los guardianes de la luna los persiguen, uno de ellos parece estar tan sorprendido que empieza a dar maromas hacia atrás en lo que parece ser un ataque de histeria. 
(10) Nuevamente nos encontramos en la superficie lunar. Los astronautas huyen aterrorizados, uno de ellos confronta incluso a los atacantes usando su paraguas como escudo y espada. Una multitud de selenitas los persigue con sus lanzas.

(11) Estamos frente al cohete que está al filo de un abismo. Ya todos están dentro, excepto el que originó la expedición porque lucha contra un monstruo lunar. Lo hace estallar y se dispone a abordar pero como no le encuentra sentido, pues están varados, toma una cuerda que cuelga de la punta de la nave $\mathrm{y}$ desciende heroicamente por ella hacia la profundidad. $\mathrm{Su}$ peso precipita la nave hacia abajo después de un emocionante balanceo. Un soldado lunar se cuelga de la parte posterior del cohete y cae con él. Llegan los selenitas, todos tienen manos de cangrejo y filosas lanzas. Ven cómo huyen sus presas y parecen muy enojados.

(12) Sobre el cielo, que tiene unas tímidas nubes en los costados, cae la nave a mucha velocidad, el profesor va colgado al frente y el selenita en la parte de atrás.

(13) El cohete cae sobre el mar y se sumerge.

(14) Estamos en la profundidad del mar, hay muchas medusas y la silueta del cohete desciende hasta tocar fondo. Despide muchas burbujas y espanta a los animales marinos. La nave rebota en el piso y asciende con lentitud.

(15) Nos encontramos en un muelle. Un barco de vapor arrastra el cohete hacia el muelle. Sobre la nave alcanzamos a ver a sus tripulantes que ondean una bandera y festejan.

Aprender a filmar fue para Méliès aprender a traducir la poesía de otros lenguajes del arte: los personajes de Luciano navegan hacia la otra orilla, hacia lo desconocido, porque quieren saber qué hay del otro lado del mar. Los astronautas con sombrillas en El viaje a la Luna del filme hacen lo mismo. Las fronteras del mundo conocido son diferentes en cada tiempo, pero ambos exploradores se topan con la misma sorpresa al llegar: un mundo inesperado que relativiza su presente. En 
ambas narraciones la "traducción", si es que la hay, significa, más que nunca, una radical separación del original. No obstante la pérdida, en los mejores momentos, es mínima.

"También vimos otro país abajo, con ciudades, ríos, mares, bosques y montañas, y dedujimos que era la tierra", narra el protagonista de Historias verdaderas. Méliès, en su libreta de cuadros, apunta: "10. Chute de l'obus dans la Lune; le clair de terre, l'aspect de la Terre vue de la Lune (Caída del obús en la Luna; el claro de la Tierra, el aspecto de la Tierra vista desde la Luna)". Las "coincidencias" a lo largo de las diferentes secuencias de la película prosiguen en diferentes ámbitos: discursivos, narrativos, en el de las estructuras formales. El contacto entre el escritor y el cineasta, aunque en fases expresivas distintas, es palpable. ¿Leyó realmente el genio del cine al incisivo narrador del siglo II o al menos tuvo contacto con alguno de sus imitadores? Todo apunta a que sí, pero quizá jamás lo sabremos porque Méliès, como buen mago, tuvo buen cuidado de ocultar sus trucos.

\section{Referencias}

Azorín, El cinematógrafo, Pre-textos, Valencia, Fundación Caja del Mediterráneo, 1995.

González Dueñas, Daniel, Méliés: el alquimista de la luz. Notas para una historia no evolucionista del cine, México, Conaculta, 2001.

Luciano de Samosata, Novelas cortas y cuentos dialogados, versión e introducción de Rafael Ramírez Torres, México, Jus, 1966.

Verne, Julio, De la tierra a la Luna. Alrededor de la Luna, pról. de María Elvira Bermúdez, México, Porrúa, 1981. 